\title{
Effects of Ethnicity and Message Framing on Colorectal Cancer Screening
}

\author{
Terry A. Cronan, Terry L. Conway, Katrina Davis and Elaina A. Vasserman-Stokes \\ San Diego State University
}

\begin{abstract}
We examined the relative effectiveness of gain- versus loss-framed videotaped messages designed to increase colorectal cancer (CRC) screening among low-income Caucasians, African Americans, and Mexican Americans. The participants were 164 people living in low-income neighborhoods. Participants watched either a gain-framed or a loss-framed videotape. They completed pre- and post-video questionnaires and received a take-home immunoassay Fecal Occult Blood Test (iFOBT) kit that they were asked to use and return by mail. Multivariate logistic regression analyses indicated that iFOBT return rates varied significantly by ethnicity $(\mathrm{p}<.002)$ and framing condition $(\mathrm{p}<.004)$. Screening kits were returned by $68.4 \%$ of Caucasians, $37.7 \%$ of African Americans, and 64.8\% of Mexican Americans; $65.0 \%$ of participants who saw the gain-framed video returned the iFOBT kit, but only $50.0 \%$ of those who saw the loss-framed video returned the kit. Framing made a difference only for Caucasians, and the direction of the difference was opposite from the direction predicted. The return rate for Latinos was similar to that for Caucasians; however, Latino rates did not vary as a function of type of framing. It is possible that message framing must be specifically targeted if it is to be effective for Latinos and African Americans.
\end{abstract}

(c) 2011 Californian Journal of Health Promotion. All rights reserved.

Keywords: Colorectal Cancer, Screening, Message Framing, Cancer Disparities

\section{Effects of Ethnicity and Message Framing on Colorectal Cancer Screening}

An estimated $90 \%$ of colorectal cancer (CRC) cases are preventable, but $\mathrm{CRC}$ remains the second leading cause of cancer-related deaths in the United States (American Cancer Society [ACS], 2009). The incidence and mortality rates of CRC rise sharply with age; $90 \%$ of the cases occur in people over age 50. The American Cancer Society (ACS, 2009) estimated that approximately 146,970 new cases of CRC and 49,920 CRC-related deaths would occur in 2009. Since 1985, the incidence of CRC in the United States has declined by nearly 20\%. This decrease is attributable to the early detection and removal of precancerous polyps, which can either prevent cancer development or lead to detection of CRC at an earlier, more treatable stage (Centers for Disease Control and Prevention [CDC], 2007; Morris, et al., 1999; Slattery, Edwards, Ma, \& Friedman, 2000).
However, screening for CRC occurs far less frequently than screening for other forms of cancer (Anderson \& May, 1995; CDC, 2008; Colombo, et al., 1997).

CRC guidelines suggest annual screening with a fecal occult blood test (FOBT) (a chemical test used to detect blood in the stool) for adults 50 or older. The Healthy People 2010 CRC screening target is for $50 \%$ of adults aged 50 or older to complete an FOBT within each 2-year period. Despite increases in overall rates of FOBT and/or lower endoscopy from 44\% in 1999 to 60.8\% in 2006 (CDC, 2008; CDC, 2001), disparities in CRC screening persist. Rates remain low for non-White ethnic groups, those with lower income and education, and those without health insurance (CDC, 2008). Indeed, in 2000, FOBT screening rate targets had yet to be met by any ethnic group (US Department of Health and Human Services, 2000). 


\section{CRC in the African American population}

African Americans have the highest death rate from CRC of any racial or ethnic group in the United States (ACS, 2007). CRC is the third leading cause of cancer death among both African American men and women. At every stage of the cancer, their survival rate is lower than that of other ethnic groups, suggesting that the standard of care for African Americans after diagnosis is lower than that for other ethnic groups (Weaver, et al., 1991). The recent emphasis on CRC screening has produced slight decreases in its incidence and mortality rates (1.3\% per year) for all groups (ACS, 2007). However, some researchers have concluded that African Americans have not shared in the progress made in early diagnosis and treatment of CRC (Weaver et al., 1991). Several factors may be responsible for the low screening rates among African Americans, including the ability to take time off from work, ease of transportation to health care facilities, selfefficacy for health-related behaviors, and cultural traditions (Baquet \& Commiskey, 1999; Hoffman-Goetz, Breen \& Meissner, 1998).

\section{CRC in the Latino Population}

Although the overall rate of CRC is lower among Latinos than among African Americans, European Americans, and Asians (ACS, 2007), first and second-generation American offspring of Latino immigrants develop CRC at rates that reach or exceed those of the United States' European American population (NCI, 2001). Low screening participation rates and lack of insurance make Latinos more likely to be diagnosed at a more advanced stage of the disease, when fewer treatment options are available (Gilliland, Hunt, \& Key, 1998). Further, research on other cancers has identified language barriers (del Carmen et al., 2007), fatalism (O'Malley, et al., 2002), and a fear of being seen as sick or weak (Bastani et al., 2001) as barriers to cancer screening that are unique to the Latino population.

\section{Behavioral Interventions}

Behavioral interventions have been conducted in attempts to increase adherence to CRC screening recommendations. These interventions have generally targeted asymptomatic, ethnically homogeneous, average-risk populations. Most have focused on increasing screening with FOBT. Several randomized controlled trials involving doctor recommendations (Bejes \& Marvel, 1992; Hardcastle, et al., 1983), use of personalized screening brochures (Denberg, et al., 2006), and telephone outreach to reduce barriers to screening (Dietrich, et al., 2007; Dietrich, et al., 2006), have succeeded in increasing screening adherence. Tailoring screening interventions to participants' backgrounds (including personal and family risks/history), knowledge, and attitudes has produced mixed results, with some tailored interventions increasing CRC screening rates (Glanz, Steffen, \& Taglialatela, 2007; Marcus, et al., 2005; Pignone, Harris, \& Kinsinger, 2000) and others not producing significant differences (Lipkus, et al., 2004; Lipkus, Crawford, Fenn, Biradavolu, \& Binder, 1999).

Few studies have examined whether there were ethnic differences in the effectiveness of the interventions. Instead, studies have tended to focus on increasing the screening rates of a particular population. For example, MitchellBeren et al. (1989) gave participants a CRC educational presentation and reading materials written at an 8th-grade reading level. Volunteer nurses from the Michigan Black Nurses' Association presented the educational components of the program to members of African American community churches. This group found that most participants believed that FOBT screening could detect CRC and that early detection could result in a cure.

In another study, Braun and colleagues (2005) tested a screening intervention using culturespecific educators, and found differences in selfreported motivation to get screened, but no differences in actual screening rates between intervention and control groups. Powe and colleagues (2004) recruited rural African Americans attending senior citizen centers and tested a cultural and self-empowerment intervention to increase CRC screening. Centers were randomly assigned to a cultural and selfempowerment group that received a five-phased intervention, a modified cultural group that received only one phase of the intervention, or to 
a control group. Women in the cultural and selfempowerment group had a significantly higher rate of returning FOBTs than did those in the modified cultural and control groups. The modified cultural group also returned significantly more FOBTs than did those in the control group. In summary, although some efforts at increasing CRC screening rates in minority populations have been made, more studies are needed to increase our understanding of the ethnic disparities that exist.

\section{Message Framing}

Message framing is one procedure for which a growing body of research indicates that small changes in the wording of recommendations to engage in health behaviors may produce significant differences in the targeted behavior (Devos-Comby \& Salovey, 2002). Careful message framing can, therefore, enhance the effectiveness of health messages (Rothman, Bartels, Wlaschin, \& Salovey, 2006). The persuasiveness of messages stressing the costs of not performing a recommended behavior (loss frame) has been compared with that of messages emphasizing the benefits of following a recommendation (gain frame) (Rothman \& Salovey, 1997). Prospect theory (Kahneman \& Tversky, 1984; Tversky \& Kahneman, 1981) suggests the conditions under which each type of frame should be more effective. It suggests that making a decision depends on how relevant the information presented is to making a choice (Schneider, et al, 2001). In general, this theory predicts that loss-famed messages should motivate decisions that involve risky or uncertain outcomes because it involves engaging in a behavior that may result in a negative outcome (e.g., finding a polyp or CRC). This theory proposes that people act to avoid risks when they consider gains or benefits, and that they are more willing to accept risks when they focus on the costs of decreasing the risks (e.g., people could avoid death from $\mathrm{CRC}$ by undergoing CRC screening).

Detection (screening) behaviors can inform individuals about a health problem. Because of the uncertainty of screening outcomes, these behaviors involve some risk (e.g., obtaining a colonoscopy involves the risk that a tumor will be found). These immediate risks may overshadow the possible benefits of detection behaviors (i.e., obtaining early treatment and avoiding death). Consistent with prospect theory, loss-framed messages should be more effective in promoting screening behaviors than gain-framed messages. Although studies have produced mixed results, loss-framed messages have been more effective in increasing mammography use (Banks et al., 1995; Schneider et al., 2001), breast self-examination (Meyerowitz \& Chaiken, 1987), and, to some extent, HIV testing (Kalichman \& Coley, 1995).

Schneider, et al., (2001) conducted a study to promote mammography screening among women over 40 years of age in an ethnically diverse low-income population. In this intervention, African American, Latina, and Caucasian women viewed gain- versus lossframed videotapes. Seven hundred and fifty-two women participated in the intervention. They were recruited from community health clinics and public housing developments and assigned randomly to conditions. Six months after viewing the video, $43 \%$ of the women who saw a loss-framed video had obtained a mammogram, while $38 \%$ of those who saw a gain-framed video had. These findings were maintained after 12 months, although they were somewhat attenuated.

The ethnic differences in CRC screening rates suggest a special need to develop and test interventions with people from different ethnic groups to determine whether they respond differently as a function of their ethnicity. The present study tested the effectiveness of persuasive messages framed either in gain (benefits) or loss (costs) terms to determine which messages were more effective in increasing screening rates among low-income African Americans, Mexican Americans, and Caucasians.

\section{Methods}

\section{Study Design and Setting}

The study was a 3 (ethnic group) by 2 (message framing) between groups design. Approximately equal numbers of Caucasian, 
African American, and Mexican American men and women participated in the study. Potential participants were told that their participation was voluntary, that their answers would be kept confidential, and that they would be paid $\$ 25.00$ for participating. All procedures were reviewed and approved by the University's Institutional Review Board.

\section{Recruitment}

Target areas for recruitment in San Diego County were determined using 2000 Census data (US Bureau of the Census, 2005) to determine eligible zip codes, based on median income and representation of African Americans, Mexican Americans, and Caucasians living in the areas. Zip codes with populations of 20,000 or greater and median incomes below $\$ 50,000$ (i.e., representing the lower half of household incomes in San Diego County) were identified. Only zip codes with high representations of each ethnic group were retained. Median incomes for the African American and Latino populations in these zip codes were calculated, and then randomly selected zip codes with matching median incomes with the highest percentage of Caucasians were chosen. This procedure was necessary because zip codes with large Caucasian populations have higher median incomes than those with large African American and Latino populations.

Within the selected zip codes, shopping centers, trolley stations, churches, and other locations where large numbers of people congregate were identified. Research assistants went to these areas, handed out flyers, and asked people who looked as though they met the inclusion criteria to participate in the study. Potential participants were asked to call the research office to confirm eligibility to participate and set up an appointment.

\section{Participants}

Study participants were 164 San Diego County residents living in low-income communities who had not had CRC screening within the recommended time frame (57 Caucasians, 53 African Americans, and 54 Mexican Americans, of whom 81 were men and 83 were women). Each ethnic group and message-framing condition contained approximately half males and half females. The criteria for participation were: 50 years of age or older; living in a zip code where the median income was $\$ 50,000$ or less (median income in San Diego county is $\$ 53,060$, (US Bureau of the Census, 2005); selfidentified Caucasian, African American, or Mexican American; had no CRC screening test within the recommended time (i.e., no FOBT within 1 year, no flexible sigmoidoscopy or double contrast barium enema within 5 years, and no colonoscopy within 10 years); no prior diagnosis of CRC; and able to read and speak English. Participants were excluded if they failed to meet any of the above criteria.

\section{Procedures}

Once eligibility for participation was confirmed, an appointment was scheduled. The office manager randomly assigned participants from each of the six gender and ethnic groups to one of the two intervention conditions (i.e., view either the gain-framed or loss-framed videotape). All others involved in the study were blind to participants' assigned intervention condition. When the participants arrived for their scheduled appointment, a research assistant explained the study and confirmed the participant's eligibility. After questions were answered and the consent form was signed, participants were asked to complete a set of questionnaires. After completing the first battery of questionnaires, the participant was taken to a room and shown either the gain- or loss-framed 9-minute videotaped intervention. When the videotape ended the participant was given a second battery of questionnaires to complete, and then each participant was provided an immunoassay FOBT (iFOBT) screening kit (addressed and stamped) with instructions on how to complete and return it in the mail. The iFOBT kits were used in this study because they detect only human blood (not dietary blood). The research assistant answered questions on completing the iFOBT; then participants were paid for their participation.

\section{Intervention}

A team of researchers that included a health communications expert worked to develop the contents of the videotapes. An actor, who was 
also an expert in health communications, was hired to act as the physician in the videotapes. The scripts were disseminated to community members and researchers and revised based on the feedback. Research team members and community members once again reviewed the final versions of the tapes.

Participants were shown either a gain- or lossframed videotaped presentation in which a physician (actor) discussed CRC and the importance of screening. The factual contents and lengths of the videotapes were the same. In the first segment of both videotapes, the information included a description of CRC, CRC incidence, symptoms of CRC, risk factors, methods of screening, and health insurance.

In the second segment, the same information was presented in both videos, but it was framed either in terms of gain (e.g., benefits of screening and early detection) or loss (e.g., disadvantages of not being screened and not detecting cancer early). In this segment, although the form of the statements varied according to framing condition, the physician (actor) covered similar content: (a) hoped the viewer had learned from the presentation how important it is to be screened for CRC, (b) recommended that each viewer get screened for CRC, (c) told participants that, even though the colonoscopy was the gold standard among CRC screening tests, the iFOBT take-home test kit also saves lives, and (d) encouraged participants to return the iFOBT kit and to seek future testing if recommended.

\section{Measures \\ Return of iFOBT. The primary outcome (dependent variable) was a dichotomous measure: $\mathrm{iFOBT}$ returned $=1$, or iFOBT not returned $=0$. The time limit for returning the iFOBT was 90 days after participation. However, no kits were returned after 90 days, so the analyses are based on all iFOBT tests returned.}

\section{Perceptions about the Videotape Presentation/Manipulation Checks}

After viewing either the gain- or loss-framed video, participants answered 21 questions assessing perceptions about the videotape in the following three areas: (a) depth of participant's processing of the video: four questions (e.g., How interested were you in the videotape? How carefully did you listen?) that were answered using a 7-point Likert scale $(1=$ not at all to $7=$ very); (b) perceptions of the physician: eight descriptive statements (e.g., $\mathrm{He}$ is a person I would trust. $\mathrm{He}$ is incompetent. $\mathrm{He}$ is well trained.) that participants rated using a 5-point Likert scale $(1=$ strongly disagree to $5=$ strongly agree); and (c) general perceptions of the video: nine questions assessing various opinions about the videotape that were answered on Likert scales tailored to each specific question (e.g., How interesting was the videotape? (rated from $1=$ not at all interesting to $5=$ extremely interesting), How much do you believe the videotape presentation applies to you? (rated from $1=$ does not apply at all to $7=$ applies very much), rate your general feelings toward the videotape. $(1=$ extremely negative to $5=$ extremely positive).

\section{Statistical Analysis}

The Statistical Package for the Social Sciences (SPSS) for Windows ${ }^{\circledR}$ Version 15.0 was used for all statistical analyses. Descriptive statistics are means and standard deviations or n's and percentages, depending on whether the variable was continuous or categorical. Mean ratings on perceptions of the videotape presentation were compared across ethnic groups and gain/loss framing conditions, using one-way analysis of variance and independent $t$ tests, respectively. Because the primary outcome measure was binary (whether or not the participant returned the iFOBT screening kit), statistical analyses examining this outcome involved crosstabulation percentages and chi square tests (bivariate relationships) or binary logistic regression (multivariate associations). Alpha for statistical significance was set at .05 a priori.

Additional analyses were conducted to assess potential confounding as a function of demographic/background factors that might differ by framing condition or ethnic group and also covary with iFOBT returns. Ten potential covariates from the pre-test survey were examined: age, education, family income, 
marital status, any insurance, family history of colon cancer, any personal diagnosis of cancer, sum of 12 possible medical conditions, self-rated health (poor to excellent), and number of times the participant had been to a doctor in the past year. Statistical tests were done to identify any significant differences by gain/loss framing condition or across ethnic groups.

\section{Results}

Analyses were conducted to address three questions: (a) how comparable were the perceptions about the videotaped presentation by participants in the three ethnic groups and across the two versions of the videotape (i.e., gain- vs. loss-framing), (b) were there differences in iFOBT return rates among ethnic groups and/or between genders, and (c) were there differences in iFOBT return rates across ethnic groups as a function of the gain- vs. loss-framing condition?

\section{Participants' Perceptions about the Videotape Presentation/Manipulation Checks}

To assess ethnic group differences in perceptions of the videotaped presentation, oneway analyses of variance were computed for all of the 21 item ratings. No significant ethnic group differences were found for the four items assessing depth of processing or the eight items assessing perceptions of the physician; of the nine general perception items, a significant difference appeared for only one item (how much do you believe that you learned from the videotape?). African Americans indicated that they learned more than Caucasians. The comparability for 20 of 21 ratings of the videotaped presentation suggests that participants perceived the video very similarly across the three ethnic groups.

To assess differences in the mean ratings of participants who viewed the gain- vs. the lossframed videos, independent $t$ tests were computed for each of the 21 perception items. Nonsignificant gain versus loss group differences were found for the four items assessing depth of processing. Of the eight items assessing perceptions of the physician, only one item (how well trained was the physician) showed a significant mean difference, with the loss group rating the physician slightly higher than the gain group. Of the nine general perception items, two items (how much did you learn from the videotape, and how engaging was the videotape) received higher mean ratings in the loss group than in the gain group; no significant gain vs. loss differences were found for the other even items. Thus 19 of 21 ratings of gain- vs. loss-framed videotapes were similar. Overall, participants in the two intervention conditions perceived their videos very similarly.

\section{iFOBT Return Rates by Ethnicity and Gender}

In the overall sample of 164 participants, $57.3 \%$ returned the iFOBT kit within the 90-day follow-up period (see Table 1). Using simple bivariate cross-tabulations, iFOBT return rates varied significantly across ethnic groups $(\mathrm{p}=$ .002 ), with kits returned by $68.4 \%$ of Caucasians, $37.7 \%$ of African Americans, and $64.8 \%$ of Mexican Americans (adjusted standardized residuals indicated that significantly more Caucasians and fewer African Americans returned kits than expected). There were no significant differences between male and female return rates $(54.3 \%$ vs. $60.2 \%$, respectively) in the overall sample. Within ethnic subgroups, gender return rates differed significantly only for Caucasians $(\mathrm{p}=.047)$, with kits returned by $55.6 \%$ of Caucasian men but by $80.0 \%$ of Caucasian women; return rates were $34.6 \%$ vs. $40.7 \%$, ns, for African American and $71.4 \%$ vs., $57.7 \%$, ns, for Mexican American men and women, respectively.

\section{iFOBT Return Rates by Message-Framing Condition}

As shown in Table 2, there was a marginally significant $(\mathrm{p}=.052)$ message-framing condition effect, with $65.0 \%$ of participants who saw the gain-framed video returning the iFOBT kit, but only $50.0 \%$ of those who saw the loss-framed video returning the iFOBT kit. At the level of bivariate cross-tabulations, conducted separately within ethnic subgroups, the message-framing condition effect varied across groups. For Caucasians, there was a highly significant $(\mathrm{p}=$ $.006)$ framing condition effect $(85.7 \%$ in the 
Table 1

iFOBT return rates within various subgroups

\begin{tabular}{|c|c|c|c|c|c|c|}
\hline & \multicolumn{4}{|c|}{ iFOBT Returned } & \multirow[t]{3}{*}{$\chi^{2}$} & \multirow[t]{3}{*}{$\mathbf{p}$} \\
\hline & \multicolumn{2}{|c|}{ No } & \multicolumn{2}{|c|}{ Yes } & & \\
\hline & $\%$ & $(\mathrm{n})$ & $\%$ & $(\mathrm{n})$ & & \\
\hline Overall Sample & $42.7 \%$ & (70) & $57.3 \%$ & (94) & & \\
\hline $\begin{array}{l}\text { Ethnicity } \\
\text { Caucasians } \\
\text { African Americans } \\
\text { Mexican Americans }\end{array}$ & $\begin{array}{l}31.6 \% \\
62.3 \% \\
35.2 \%\end{array}$ & $\begin{array}{l}(18) \\
(33) \\
(19)\end{array}$ & $\begin{array}{l}68.4 \% \\
37.7 \% \\
64.8 \%\end{array}$ & $\begin{array}{l}(39) \\
(20) \\
(35)\end{array}$ & 12.42 & .002 \\
\hline $\begin{array}{l}\text { Gender } \\
\text { Males } \\
\text { Females }\end{array}$ & $\begin{array}{l}45.7 \% \\
39.8 \%\end{array}$ & $\begin{array}{l}(37) \\
(33)\end{array}$ & $\begin{array}{l}54.3 \% \\
60.2 \%\end{array}$ & $\begin{array}{l}(44) \\
(50)\end{array}$ & 0.59 & .443 \\
\hline $\begin{array}{c}\text { Gender within Ethnic } \\
\text { Caucasians } \\
\text { Males } \\
\text { Females }\end{array}$ & $\begin{array}{l}44.4 \% \\
20.0 \%\end{array}$ & $\begin{array}{l}(12) \\
(6)\end{array}$ & $\begin{array}{l}55.6 \% \\
80.0 \%\end{array}$ & $\begin{array}{l}(15) \\
(24)\end{array}$ & 3.93 & .047 \\
\hline $\begin{array}{c}\text { African Americans } \\
\text { Males } \\
\text { Females }\end{array}$ & $\begin{array}{l}65.4 \% \\
59.3 \%\end{array}$ & $\begin{array}{l}(17) \\
(16)\end{array}$ & $\begin{array}{l}34.6 \% \\
40.7 \%\end{array}$ & $\begin{array}{l}(9) \\
\text { (11) }\end{array}$ & 0.212 & .646 \\
\hline $\begin{array}{c}\text { Mexican Americans } \\
\text { Males } \\
\text { Females }\end{array}$ & $\begin{array}{l}28.6 \% \\
42.3 \%\end{array}$ & $\begin{array}{c}(8) \\
(11)\end{array}$ & $\begin{array}{l}71.4 \% \\
57.7 \%\end{array}$ & $\begin{array}{l}(20) \\
(15)\end{array}$ & 1.115 & .291 \\
\hline
\end{tabular}

gain-framed condition vs. $51.7 \%$ in the lossframed condition returned iFOBT kits), but no significant condition effect for either African Americans $(42.3 \%$ vs. $33.3 \%$, ns) or Mexican Americans $(65.4 \%$ vs. $64.3 \%$, ns). Males assigned to the gain-framed condition were more likely than males in the loss-framed condition to return the iFOBT kits, but this difference was not statistically significant $(\mathrm{p}=.089)$. However, gender-specific condition effects held only for Caucasians, with $76.9 \%$ vs. $35.7 \%(\mathrm{p}=.031)$ of Caucasian men in the gain- versus loss-framed conditions, respectively, returning iFOBT kits; for Caucasian women, $93.3 \%$ vs. $66.7 \%$ ( $\mathrm{p}=$ .068 ) of those in the gain- vs. loss-framed conditions, respectively, returned iFOBT kits. There were no significant gender-specific condition effects for African American or Mexican American men and women (see Table 2).

\section{Multivariate Prediction of iFOBT Return Rates by Ethnicity and Message-Framing Condition}

To examine the independent effects of message framing, ethnicity, and condition-by-ethnicity interaction on whether or not the iFOBT screening kits were returned, a binary logistic regression was computed. Gender was not included in this multivariate regression because it was not associated with $\mathrm{iFOBT}$ return rates by framing condition at the bivariate level (see Table 2). Also, because the interaction of condition and ethnicity was not significant in the full model, the logistic regression was re-run with only the condition and ethnicity main effects (see Table 3). Both message framing condition $(\mathrm{p}=.044)$ and ethnicity $(\mathrm{p}=.002)$ were independently associated with returning the iFOBT screening kits. Overall, participants in the gain-framed video condition had 1.97 greater 
Table 2

iFOBT return rates within various subgroups by Gain- and Loss-Framed video conditions

\begin{tabular}{|c|c|c|c|c|c|c|c|c|c|c|}
\hline & \multicolumn{4}{|c|}{ Gain-Framed Video Condition } & \multicolumn{4}{|c|}{ Loss-Framed Video Condition } & \multirow[t]{3}{*}{$\chi^{2}$} & \multirow[t]{3}{*}{$p$} \\
\hline & \multicolumn{4}{|c|}{ iFOBT Returned } & \multicolumn{4}{|c|}{ iFOBT Returned } & & \\
\hline & \multicolumn{2}{|c|}{ No } & \multicolumn{2}{|c|}{ Yes } & \multicolumn{2}{|c|}{ No } & \multicolumn{2}{|c|}{ Yes } & & \\
\hline & $\%$ & $(\mathrm{n})$ & $\%$ & $(\mathrm{n})$ & $\%$ & $(\mathrm{n})$ & $\%$ & $(\mathrm{n})$ & & \\
\hline Overall Sample & $35.0 \%$ & (28) & $65.0 \%$ & (52) & $50.0 \%$ & $(42)$ & $50.0 \%$ & $(42)$ & 3.77 & .052 \\
\hline \multicolumn{11}{|l|}{ Ethnicity } \\
\hline Caucasians & $14.3 \%$ & (4) & $85.7 \%$ & (24) & $48.3 \%$ & (14) & $51.7 \%$ & $(15)$ & 7.62 & .006 \\
\hline $\begin{array}{l}\text { African } \\
\text { Americans }\end{array}$ & $57.7 \%$ & (15) & $42.3 \%$ & (11) & $66.7 \%$ & (18) & $33.3 \%$ & (9) & 0.45 & .500 \\
\hline $\begin{array}{l}\text { Mexican } \\
\text { Americans }\end{array}$ & $34.6 \%$ & (9) & $65.4 \%$ & (17) & $35.7 \%$ & (10) & $64.3 \%$ & (18) & 0.01 & .933 \\
\hline \multicolumn{11}{|l|}{ Gender } \\
\hline Males & $35.9 \%$ & (14) & $64.1 \%$ & (25) & $54.8 \%$ & (23) & $45.2 \%$ & (19) & 2.90 & .089 \\
\hline Females & $34.1 \%$ & (14) & $65.9 \%$ & (27) & $45.2 \%$ & (19) & $54.8 \%$ & (23) & 1.07 & .302 \\
\hline \multicolumn{11}{|l|}{$\begin{array}{l}\text { Gender within } \\
\text { Ethnic Groups }\end{array}$} \\
\hline Cauc. Males & $23.1 \%$ & (3) & $76.9 \%$ & (10) & $64.3 \%$ & (9) & $35.7 \%$ & (5) & 4.64 & .031 \\
\hline Cauc. Females & $6.7 \%$ & (1) & $93.3 \%$ & (14) & $33.3 \%$ & (5) & $66.7 \%$ & (10) & 3.33 & .068 \\
\hline Afr. Am. Males & $53.8 \%$ & (7) & $46.2 \%$ & (6) & $76.9 \%$ & (10) & $23.1 \%$ & (3) & 1.53 & .216 \\
\hline Afr. Am. Fem. & $61.5 \%$ & (8) & $38.5 \%$ & (5) & $57.1 \%$ & (8) & $42.9 \%$ & (6) & 0.05 & .816 \\
\hline Mex. Am. Males & $30.8 \%$ & (4) & $69.2 \%$ & (9) & $26.7 \%$ & (4) & $73.3 \%$ & (11) & 0.06 & .811 \\
\hline Mex. Am. Fem. & $38.5 \%$ & (5) & $61.5 \%$ & (8) & $46.2 \%$ & (6) & $53.8 \%$ & $(7)$ & 0.16 & .691 \\
\hline
\end{tabular}

odds of returning the iFOBT kit than participants in the loss-framed video condition. The significant ethnicity effect indicated that the odds of returning the iFOBT kit were 3.7 times higher for Caucasians than for African Americans (i.e., inverse of the odds ratio of 0.27 $=3.7$ ) and 3.1 times higher for Mexican Americans than for African Americans, although there was not a significant difference in the odds of returning the iFOBT kits between Caucasians and Mexican Americans.

Because iFOBT return rates could potential vary by demographic or background factors, it was important to examine potential confounding that could occur due to differences across experimental conditions or ethnic groups. Ten potential covariates (age, education, family income, marital status, any insurance, family history of colon cancer, any personal diagnosis of cancer, sum of 12 possible medical conditions, self-rated health, and number of times the participant had been to a doctor in the past year) were tested to determine any significant differences by gain/loss framing condition or across the three ethnic groups. None of the 10 demographic/background variables differed significantly $(p>.05)$ between the framing conditions, indicating that the random assignment to experimental condition was effective in producing comparable groups pre-exposure to the video conditions (and ruling out potential confounding due to demographic/background variables). 
Table 3

Logistic regression results predicting iFOBT return rates by message-framing condition and ethnicity ${ }^{\mathrm{a}}$

\begin{tabular}{rrrr}
\hline OR & $95 \%$ & CI & p \\
\hline
\end{tabular}

Framing Condition:

Gain-Framed vs.

Loss-Framed $^{\mathrm{b}}$

$1.96 \quad(1.019$,

3.792)

.044

Ethnicity:

\begin{tabular}{|c|c|c|c|}
\hline $\begin{array}{l}\text { African Americans vs. } \\
\text { Caucasians }\end{array}$ & .270 & $\begin{array}{l}(0.121 \\
0.602)\end{array}$ & .001 \\
\hline $\begin{array}{l}\text { Mexican Americans vs. } \\
\text { Caucasians }\end{array}$ & .852 & $\begin{array}{l}(0.383 \\
1.896)\end{array}$ & .695 \\
\hline $\begin{array}{l}\text { African Americans vs. } \\
\text { Mexican Americans }{ }^{\mathrm{b}}\end{array}$ & .317 & $\begin{array}{l}(0.142 \\
0.706)\end{array}$ & .005 \\
\hline
\end{tabular}

${ }^{a}$ Logistic regression results are for the model without the condition-by-ethnicity interaction effect because it was not significant $(\mathrm{p}>.05)$ in the initial analysis.

${ }^{\mathrm{b}}$ Reference group.

For the non-randomly assigned ethnic groups, four significant differences were found: age, education, family income, and marital status (Caucasians were older; Hispanics had lower education; African Americans had lower income and were less likely to be married). No significant differences were found for the other six demographic/background variables. To confirm that ethnic group differences in age, education, income, and marital status were not confounding the framing condition and ethnicity effects on iFOBT returns (Table 3), additional multivariate logistic regressions were conducted to test the independent effects of the framing and ethnicity factors, controlling for these demographic variables. A series of logistic regressions were run using backward elimination procedures to remove (one at a time) nonsignificant terms in the model. Only family income remained a significant $(\mathrm{p}=.051)$ covariate, and the odds ratios and p-values for the framing condition and ethnicity main effects remained virtually identical to those reported in Table 3 (indicting no confounding effects of demographic/background factors).

\section{Discussion}

This was the first study designed specifically to compare iFOBT return rates among African Americans, Mexican Americans, and Caucasians, all of whom lived in low-income neighborhoods. The overall iFOBT return rate in this study was $57.3 \%$; this rate is consistent with rates in other interventions designed to increase CRC screening (Dietrich et al., 2006; King, Fairbrother, Thompson, \& Morris, 1992; Pye, Christie, Chamberlain, Moss, \& Hardcastle, 1988). The return rates varied as a function of ethnicity. Caucasians and Mexican Americans had significantly higher return rates than African Americans. The return rates in our study for Caucasians and Latinos are higher than those found in other CRC screening interventions, even though we focused on low-income participants. This is somewhat surprising because people who come from underrepresented ethnic groups and/or who are from low-income groups are less likely to be screened for cancer (Hoffman-Goetz, Breen, \& Meissner, 1998).

In this study African Americans were less likely than Caucasians and Mexican Americans to return the iFOBT screening kit, regardless of whether they viewed a positively framed or negatively framed CRC intervention video. Kreuter and McClure (2004) suggest that, if the information provided in the videotape had been tailored to African Americans, it might have increased their concern about prevention and, therefore, the likelihood that they would have engaged in preventive screening. Other researchers have suggested that future research needs to target cultural sensitivity in order to increase the salience of prevention to the group (Resnicow, Baranowski, Ahluwalia, \& Braithwaite, 1999); this could be accomplished by having an actor of the same ethnic group tailor the message to the culture of the audience.

Caucasians who viewed the positively framed message were more likely than those who viewed a negatively framed message to return their iFOBT. We expected that loss-framed 
messages would be more effective in increasing iFOBT return rates because, according to prospect theory, CRC screening is a detection behavior with uncertain consequences (Rothman \& Salovey, 1997). Only one other study tested the effects of framing on CRC screening; it revealed no statistically significant differences between gain- and loss-framed messages (Myers et al., 1991). Thus, it is possible that the effects of message framing on screening for CRC may differ from those on screening for other cancers.

One explanation for the findings of the present study is that people from different ethnic backgrounds may process information differently. However, when the perceptions about the videotape presentation were examined, there was only one difference across ethnic groups: African Americans indicated that they learned more than Caucasians. Given this finding, we might have expected the iFOBT return rates of African Americans to be similar to those of Caucasians and Latinos. Future studies should examine other factors that may be responsible for differences in CRC screening. This is particularly important for African Americans because the incidence and mortality rates of CRC are highest for this group.

Male and female return rates did not differ significantly in the overall sample. However, there was a gender difference among Caucasians. Caucasian women were more likely than Caucasian men to return their iFOBT. This finding is consistent with other studies indicating that women comply with CRC screening recommendations better than men (King, et al., 1992; Mant et al., 1992; Myers et al., 1991; Box et al., 1984; Lallemand et al., 1984; Hardcastle et al., 1983;). Future researchers should continue to examine gender differences among underrepresented groups to determine how culture affects gender differences in screening.

One of the limitations of the present study was the relatively small number of participants within the subgroups. Although significant main effects of message framing and ethnicity on iFOBT screening were found, there was limited power to explore and detect potential moderators of these effects. For example, factors such as perceived cancer risks, perceived screening efficacy, or treatment expectations may moderate message-framing effects, and moderator effects may differ across ethnic groups. A much larger sample would be required to have the power to detect such interactions. Another limitation of the current study related to having only one gain and one loss videotape version. Further exploration of specific message characteristics used "gain" or "loss" frameworks that are most efficacious in motivating cancer screening behavior would be valuable.

In summary, this study is the first to examine ethnic differences in CRC screening as a function of message framing. The findings suggest that message framing is important only for some groups. The intervention used in this study appears to be effective because screening rates were similar to those in other intervention studies, even though this study focused on underrepresented and low-income groups that generally have lower cancer screening rates. More research is needed to find effective methods to increase CRC screening, especially for African Americans. It appears likely that a combination of gain- and loss-framing, designed to maximize the perceived benefit to cost ratio of obtaining screening, will turn out to be the most effective way to increase screening.

\section{Implications for Practice}

This study indicates that it is particularly important for physicians to talk with their African American patients about the importance of screening and to recommend that the screening be performed at regular intervals. If possible, someone who can tailor the message for African Americans should deliver the message. Although this implication is not directly supported by the results of the present study, it is likely that both the benefits of screening and the dangers of failing to be screened should be described to produce the strongest possible message. The present study replicates the results of previous studies indicating that interventions increase screening rates; well over half of our participants, none of whom had previously been screened within the recommended interval, returned their iFOBT's. 
Cronan,T.A., Conway, T.L., Davis, K., \& Vasserman-Stokes, E.A., / Californian Journal of Health Promotion 2011, Volume 9.

Issue 1, 86-98

The implication is that screening interventions do save lives.

\section{References}

American Cancer Society (2007). Cancer Facts and Figures 2007. Atlanta, GA: American Cancer Society.

American Cancer Society. (2010, February 16). Detailed Guide: Colon and Rectum Cancer 2009. Retrieved March 9, 2009, from http://www.cancer.org/docroot/cri/content/cri_2_4_1x_what_are the key_statistics_for_colon_and_rectum_cancer.asp

Anderson, L.M., \& May, D.S. (1995). Has the use of cervical, breast, and colorectal cancer screening increased in the United States? American Journal of Public Health, 85(6), 840-842.

Banks, S. M., Salovey, P., Greener, S., Rothman, A. J., Moyer, A., Beauvais, J., \& Epel, E. (1995). The effects of message framing on mammography utilization. Health Psychology, 14(2), 178-184.

Baquet, C.R., \& Commiskey, P. (1999). Colorectal cancer epidemiology in minorities: A review. Journal of the Association for Academic Minority Physicians, 10(3), 51-58.

Bejes, C., \& Marvel, M. K. (1992). Attempting the improbable: Offering colorectal cancer screening to all appropriate patients. Family Practice Research Journal, 12(1), 83-90.

Box, V., Nichols, S., Lallemand, R. C., Pearson, P., \& Vakil, P. A. (1984). Haemoccult compliance rates and reasons for non-compliance. Public Health, 98(1), 16-25.

Braun, K.L., Fong, M, Kaanoi, M.E., Kamaka, M.L., Gotay, C.C. (2005). Testing a culturally appropriate, theory-based intervention to improve colorectal cancer screening among Native Hawaiians. Preventive Medicine, 40, 619-27.

Centers for Disease Control and Prevention. (2001). Trends in screening for colorectal cancer --- Unites States, 1997 and 1999. MMWR Weekly, 50(09), 162-166.

Centers for Disease Control and Prevention. (2007). 2006/2007 Colorectal Cancer Initiatives, Division of Cancer Prevention and Control.

Centers for Disease Control and Prevention. (2008). Use of Colorectal Cancer Test --- United States, 2002, 2004, 2006. MMWR Weekly, 57(10), 253-258.

Colombo, L., Corti, G., Magri, F., Marocchi, A., Brambilla, P., Crespi, C., Manieri, L., Ghezzi, S., Giannone, D., Merlino, L., \& Mocarelli, P. (1997). Results of a pilot study of endoscopic screening of first degree relatives of colorectal cancer patients in Italy. Journal of Epidemiology \& Community Health, 51(4), 453-458.

del Carmen M, Findley M, Muzikansky A, et al. (2007). Demographic, risk factor, and knowledge differences between Latinas and non-Latinas referred to colposcopy. Gynecologic Oncology. 104, 70-76.

Denberg, T., Coombes, J., Byers, T., Marcus, A., Feinberg, L., Steiner, J., \& Ahnen, D. (2006). Effect of a mailed brochure on appointment-keeping for screening colonoscopy. Annals of Internal Medicine, 145(12), 895-900.

Devos-Comby, L., \& Salovey, P. (2002). Applying persuasion strategies to alter HIV-relevant thoughts and behavior. Review of General Psychology, 6(3), 287-304.

Dietrich, A. J., Tobin, J. N., Cassells, A., Robinson, C. M., Greene, M. A., Sox, C. H., Beach, M. L., DuHamel, K. N., \& Younge, R. G. (2006). Telephone care management to improve cancer screening among low-income women. Annals of Internal Medicine, 144(8), 563-570.

Dietrich, A. J., Tobin, J. N., Cassells, A., Robinson, C. M., Reh, M., Romero, K. A., Flood, A. B., \& Beach, M. L. (2007). Translation of an efficacious cancer-screening intervention to women enrolled in a Medicaid managed care organization. Annals of Family Medicine, 5(4), 320-327.

Gilliland, F. D., Hunt, W. C., \& Key, C. R. (1998). Trends in the survival of American Indian, Hispanic, and Non-Hispanic White cancer patients in New Mexico and Arizona, 1969-1994. Cancer, 82(9), 1769-1783

Glanz, K., Steffen, A. D., \& Taglialatela, L. A. (2007). Effects of colon cancer risk counseling for firstdegree relatives. Cancer Epidemiol Biomarkers Prev, 16(7), 1485-1491. 
Cronan,T.A., Conway, T.L., Davis, K., \& Vasserman-Stokes, E.A., / Californian Journal of Health Promotion 2011, Volume 9.

Issue 1, 86-98

Hardcastle, J. D., Farrands, P. A., Balfour, T. W., Chamberlain, J., Amar, S. S., \& Sheldon, M. G. (1983). Controlled trial of faecal occult blood testing in the detection of colorectal cancer. Lancet, 2(8340), 1-4.

Hoffman-Goetz, L., Breen, N. L., \& Meissner, H. (1998). The impact of social class on the use of cancer screening within three racial/ethnic groups in the United States. Ethnicity \& Disease, 8(1), 43-51.

Kahneman, D., \& Tversky, A. (1984). Choices, values, and frames. American Psychologist, 39(4), 341350.

Kalichman, S. C., \& Coley, B. (1995). Context framing to enhance HIV-antibody-testing messages targeted to African American women. Health Psychology, 14(3), 247-254.

King, J., Fairbrother, G., Thompson, C., \& Morris, D. L. (1992). Colorectal cancer screening: Optimal compliance with postal faecal occult blood test. Australian \& New Zealand Journal of Surgery, 62(9), 714-719.

Kreuter, M.W., \& McClure, S.M. (2004). The role of culture in health communication. Annual Review of Public Health, 24, 439-455.

Lallemand, R. C., Vakil, P. A., Pearson, P., \& Box, V. (1984). Screening for asymptomatic bowel cancer in general practice. British Medical Journal Clinical Research Education, 288(6410), 31-33.

Lipkus, I. M., Skinner, C. S., Dement, J., Pompeii, L., Moser, B., Samsa, G. P., \& Ransohoff, D. (2004). Increasing colorectal cancer screening among individuals in the carpentry trade: Test of risk communication interventions. Preventive Medicine, 40, 489-501.

Lipkus, I. M., Crawford, Y., Fenn, K., Biradavolu, M., \& Binder, R. A. (1999). Testing different formats for communicating colorectal cancer risk. Journal of Health Communication, 4, 311-324.

Mant, D., Fuller, A., Northover, J., Astrop, P., Chivers, A., Crockett, A., Clements, S., \& Lawrence, M. (1992). Patient compliance with colorectal cancer screening in general practice. British Journal of General Practice, 42(354), 18-20.

Marcus, A. C, Mason, M., Wolfe, P., Rimer, B. K., Lipkus, I., Strecher, V., Warneke, R., Morra, M. E., Allen, A. R., Davis, S. W., Gaier, A., Graves, C., Julesberg, K., Nguyen, L., Perocchia, R., Speyer, J. B., Wagner, D., Thomsen, C., \& Bright, M. A. (2005). The efficacy of tailored print materials in promoting colorectal cancer screening: Results from a randomized trial involving callers to the national cancer institute's cancer information service. Journal of Health Communication, 10, 83-104.

Meyerowitz, B. E., \& Chaiken, S. (1987). The effect of message framing on breast self-examination attitudes, intentions, and behavior. Journal of Personality \& Social Psychology, 52(3), 500-510.

Mitchell-Beren, M. E., Dodds, M. E., Choi, K. L., \& Waskerwitz, T. R. (1989). A colorectal cancer prevention, screening, and evaluation program in community black churches. CA: A Cancer Journal for Clinicians, 39(2), 115-118.

Morris, C.R., Cohen, R., Perkins, C.I., Allen, M., Kwong, S.L., Schlag, R., \& Wright, W.E. (1999). California Cancer Registry. Cancer in California, 1988-1996. Department of Health Services, Cancer Surveillance Section. Sacramento, CA.

Myers, R. E., Ross, E., Wolf, T. A., Balshem, A., Jepson, C., \& Millner, L. (1991). Behavioral interventions to increase adherence in colorectal cancer screening. Medical Care, 29(10), 10391050 .

National Cancer Institute (2001). Question and answers about screening, early detection, and treatment for colorectal cancer. Cancer Net. Retrieved November 7, 2001, from the World Wide Web: http://www.cancernet.nci.nih.gov.

O'Malley, A.S., Renteria-Weitzman, R., Huerta, E.E., et al. (2002). Patient and provider priorities for cancer prevention and control: a qualitative study in mid-Atlantic Latinos. Ethnicity and Disease, 12, 383-391.

Pignone, M., Harris, R., \& Kinsinger, L. (2000). Videotape-based decision aid for colorectal cancer screening. Annals of Internal Medicine, 133(10), 761-769.

Powe, B. D., Ntekop, E. and Barron, M. (2004), An Intervention Study to Increase Colorectal Cancer Knowledge and Screening Among Community Elders. Public Health Nursing, 21, 435-442. 
Pye, G., Christie, M., Chamberlain, J. O., Moss, S. M., \& Hardcastle, J. D. (1988). A comparison of methods for increasing compliance within a general practitioner based screening project for colorectal cancer and the effect on practitioner workload. Journal of Epidemiology \& Community Health, 42(1), 66-71.

Resnicow, K., Baranowski, T., Ahluwalia, J., \& Braithwaite, R., (1999). Cultural sensitivity in public health: defined and demystified. Ethnicity \& Disease, 9, 10-21.

Rothman, A. J., \& Salovey, P. (1997). Shaping perceptions to motivate healthy behavior: The role of message framing. Psychological Bulletin, 121(1), 3-19.

Rothman, A.J., Bartels, R.D., Wlaschin, J., \& Salovey, P. (2006). The strategic use of gain- and lossframed messages to promote healthy behavior: How theory can inform practice. Journal of Communication, 56, S202-S220.

Schneider, T. R., Salovey, P., Apanovitch, A. M., Pizarro, J., McCarthy, D., Zullo, J., \& Rothman, A. J. (2001). The effects of message framing and ethnic targeting on mammography use among lowincome women. Health Psychology, 20(4), 256-266.

Slattery, M.L., Edwards, S.L., Ma, K.N., \& Friedman, G.D. (2000). Colon cancer screening, lifestyle, and risk of cancer. Cancer Causes \& Control, 11(6), 555-563.

Tversky, A., \& Kahneman, D. (1981). The framing of decisions and the psychology of choice. Science, $211(4481), 453-458$.

US Bureau of the Census. American Factfinder 2005 American Community Survey Data Profile Highlights. San Diego County California. www.factfinder.census.gov.

US Department of Health and Human Services (2000). Healthy people 2010: National Health Promotion and Disease Prevention Objectives. Public Health Service. Washington, DC: Government Printing Office.

Weaver, P., Harrison, B., Eskander, G., Jahan, M. S., Tanzo, V., Williams, W., et al. (1991). Colon cancer in blacks: A disease with a worsening prognosis. Journal of the National Medical Association, 83(2), 133-136.

Weinrich, S. P. (1990). Predictors of older adults' participation in fecal occult blood screening. Oncology Nursing Forum, 17(5), 715-720.

Weinrich, S. P., Weinrich, M. C., Stromborg, M. F., Boyd, M. D., \& Weiss, H. L. (1993). Using elderly educators to increase colorectal cancer screening. Gerontologist, 33(4), 491-496.

\author{
Author Information \\ Terry A. Cronan, Ph.D.* \\ San Diego State University \\ Health Outcome Studies \\ 6505 Alvarado Road, Suite 110 \\ San Diego, CA 92120, USA. \\ Telephone (619) 594-6915 \\ Fax (619) 594-1247 \\ Email: \\ Terry L. Conway, Ph.D. \\ San Diego State University \\ Katrina Davis, M.A. \\ San Diego State University \\ Elaina A. Vasserman-Stokes, M.A. \\ San Diego State University \\ * corresponding author
}

